\title{
ANALYSIS OF STEEL BRIDGES WITH RECTANGULAR WEB OPENINGS: FINITE ELEMENT INVESTIGATION
}

\author{
Mohamed Abdel-Basset Abdo \\ Civil Engineering Department, Faculty of Engineering, Assiut University, \\ Assiut, Egypt.
}

(Received August 11, 2009 Accepted December 23, 2009).

\begin{abstract}
This study is concerned with parametric study of the effect of rectangular web openings on the response of steel bridges with cross frames and bottom lateral bracings. The study includes studying the deflections of steel bridges as an important factor of static response and the frequencies of steel bridges as an important factor of dynamic response. The influence of rectangular web openings of various sizes and numbers on the response of steel bridges is investigated with and without horizontal stiffeners (reinforcements). Buckling and instability failures of the steel beams are not considered in the present analysis. Based on the analysis results of steel bridges with cross frames and bottom lateral bracings, it is shown that existence of only one rectangular (square) web opening at mid span has almost negligible effect on the maximum deflections at mid span and small effect on the frequencies of bridge models. However, existence of more than one square or rectangular web opening leads to great increase in the deflection at mid span and considerable decrease in frequencies. Also, an increase in the ratio of web opening height to web height leads to great increase in the maximum deflection of bridge model. On the other hand, horizontal stiffeners (reinforcements) above and below web openings improves both static and dynamic response of steel bridge models especially, for multiple web openings. However, the effect of reinforcement stiffness is more pronounced for static response.
\end{abstract}

KEYWORDS: Analysis, steel bridges, rectangular web openings, finite element, investigation.

\section{INTRODUCTION}

In modern buildings, openings are frequently required to be provided in structural members so that building services may be incorporated into structural zones for simplified layout and installation. The presence of large web openings may have a severe penalty on the load carrying capacities of floor beams, depending on the shapes, the dimensions and the locations of the openings. Both rectangular and circular openings are commonly used, and reinforcements around the web openings may be provided as necessary through rational design [1]. Indeed, web openings reduce the stiffness of a member at an opening by lowering both of gross moment of inertia at the opening and cross sectional area available for carrying shear.

The lower gross moment of inertia results in increased curvature at openings subjected to bending. Furthermore, the loss of material for carrying shear results in differential vertical (Vierendeel) deflections between the ends of openings subjected to 
shear. The use of reinforcement at an opening can restore the gross moment of inertia [2].

A large amount of research efforts on the structural behaviour of steel and composite beams with web openings have been reported in the literature over the last three decades. Most of the work has examined the effects of web openings on steel beams. Problems associated with cutting openings in webs of steel beams have been considered by Redwood and Cho [3]. They resulted in approximate method for the design of steel beams with web openings. Shan et al. [4] have investigated bending and shear behaviour of web elements with openings for cold-formed steel beams. They recommended using a modified interaction equation employed by AISI (American Iron and Steel Institute) specification to account for the influence of the web opening. Chung et al. [1] have investigated the effect of circular web openings on beams' shear and bending load carrying capacities. Liu and Chung [5] have investigated the behaviour of steel beams with large web openings of various shapes and sizes using finite element method. They found that all steel beams with web openings of various shapes and sizes behave similarly among each other in terms of deformed shapes under a wide range of applied moment and shear force. Hagen et al. [6] have carried numerical simulations to determine the ultimate shear capacity of steel plate girders with large web openings. Moreover, Hagen and Larsen [7] have given equations and guidelines for the ultimate shear capacity of steel plate girders with large web openings.

Other research work has examined the effect of web openings on composite beams. Fahmy [8] has investigated the response of composite beams with unreinforced rectangular web openings. He showed that the strength of composite beam decreases with the increase of opening length and height. Benitez et al. [2] have studied the deflections of composite beams with web openings. They found that ignoring both the web opening and shear deformation could lead to significant error. Also, they found that for small openings, bending deformations are negligible. Conversely, for large openings, the effect of shear deformations are negligible. Chung and Lawson [9] have given simplified design tables of composite beams with large web openings to Eurocode 4. They recommended the geometry and arrangement of web openings as well as reinforcement. Park et al. [10] have investigated the ultimate shear strength of ribbed slab composite beams with web openings. They found that the maximum shear capacity is approximated as the sum of the individual shear capacity of the steel beam and the concrete slab. Hassan [11] has studied the flexural behaviour of composite beams with stiffened and un-stiffened circular web openings. The author recommended to minimize the height of the opening relative to the beam depth and use stiffeners around the web openings.

As the aforementioned summary indicates, most of the researches have been carried out on static response of individual steel or composite beams . However, rare studies have been carried on the effects of web openings on static and free vibration response of steel bridges. So, the objective of this paper is to investigate the influence of web openings on the free vibration response as well as the maximum deflections of steel bridges with cross frames and bottom lateral bracings. Indeed, understanding how steel bridges with web openings respond in static and dynamic can help reduce stresses and displacements and give advice to designers at the scheme design stage. A careful numerical study is carried out by using the finite element method to analyze the 
behaviour of steel bridges with rectangular web openings of different sizes and numbers. Both steel webs and flanges of beams are modeled using shell elements. Cross frames and bracing members are modeled using beam elements. The convergence of frequencies is obtained via comparing the results of different meshes.

\section{FINITE ELEMENT ANALYSIS}

\subsection{Bridge Geometry}

The basic model of the bridge used in this analysis consists of two steel girders, $2 \mathrm{~m}$ spacing between web centre-lines, and simple span of $12 \mathrm{~m}$ and total length of $12.2 \mathrm{~m}$. Webs of the girders are $100 \times 1.0 \mathrm{~cm}$ and each of top and bottom flanges is $40 \times 2 \mathrm{~cm}$. The steel beams are connected with cross frames of $1 \mathrm{~L} 70 \times 70 \times 7$ spaced at intervals of $4 \mathrm{~m}$. Also, bottom lateral bracings are provided with $1 \mathrm{~L} 120 \times 120 \times 12$. Indeed X-type cross frames and lateral bracings are recommended for both horizontal and curved steel bridges by many researchers, e.g., [12] and [13]. So, only bridges having X-shaped cross diaphragms and lateral bracings are considered in the current work. The bridge is designed according to Egyptian Code of Practice (ECP) for steel construction and bridges [14]. A cross section of the finite element model representing the basic section of the bridge is shown in Fig. 1(a). The material properties of steel are: density, $\rho=$ $7850 \mathrm{~kg} / \mathrm{m}^{3}$; yield stress, $\sigma_{y}=360 \mathrm{MPa}$; Young's modulus, $E=210 \mathrm{GPa}$; Poisson's ratio, $v=0.3$.

\subsection{Model Description}

The finite-element modeling in the present study was carried out using the MARC/Mentat package [15], [16]. A three-dimensional finite element model with the following characteristics had been used: (1) a four-node thick shell element with six degrees of freedom at each node (element 75) was used to model steel webs and steel flanges; (2) a two-node beam element with six degrees of freedom at each node (element 52) was used to model both cross frames and bracing members. One of the supports of the system is hinged and the other is roller.

Three different meshes are investigated and both the maximum deflection and the fundamental frequencies are convergent for finer mesh. An isometric view of the finite element model of the basic section (without web opening) is shown in Fig. 1(b), with 4733 nodes and 4880 elements (10 elements for web and 4 elements for each flange and 122 shell elements along the span). The height of cross frames is 8 shell elements of the web height and each beam member is divided into 4 elements. In present study, the following assumptions are considered: (1) the bridge models are simply-supported; (2) the bridges have uniform cross sectional area between support lines; (3) all materials are elastic and homogenous; (4) webs of the steel girders are vertical, and (5) deformations are assumed to remain within the limits of small displacement theory; (6) the own weight of steel beams, cross frames, and lateral bracings and additional dead load are considered. It is important to mention that the dead loads have considerable influence on lower frequencies of beams, especially the fundamental one and this effect increases with the increase of dead load, Abdo [17]. Fig. 1(c) shows an elevation of the steel bridge with one web opening $(100 \times 50 \mathrm{~cm})$. 


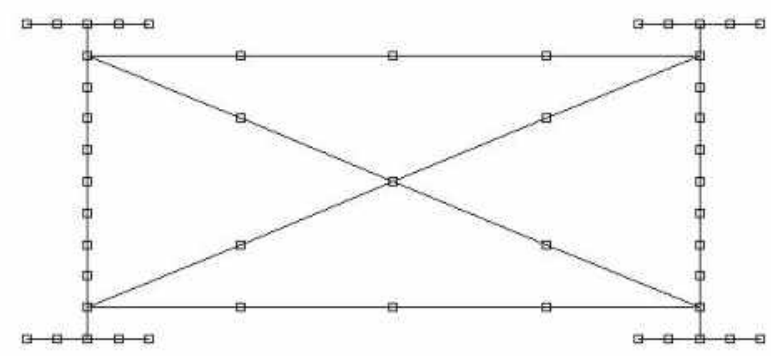

(a) Finite element representation of bridge cross section.

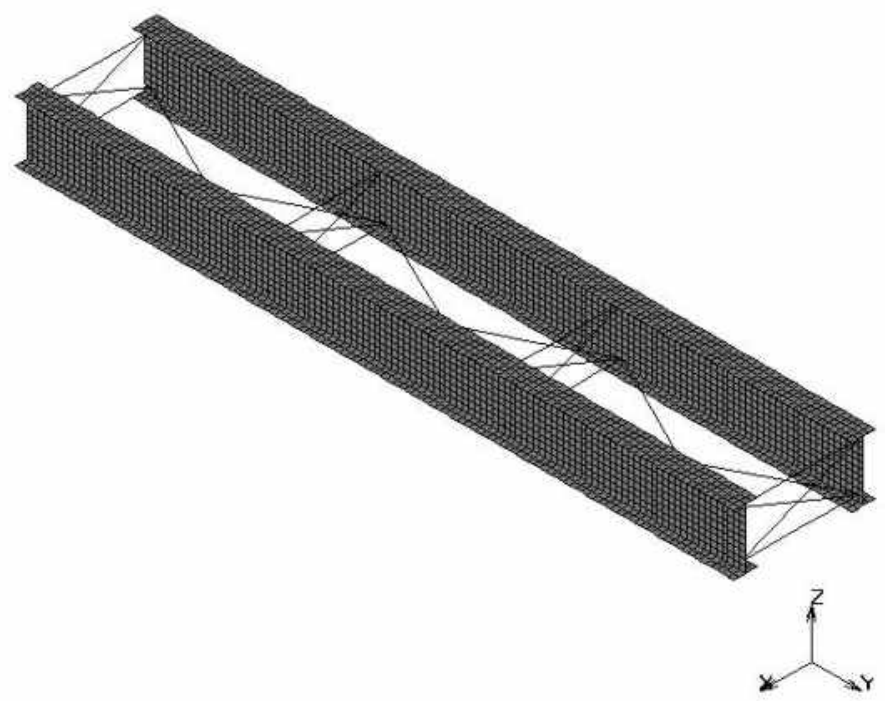

(b) Isometric view of the bridge.

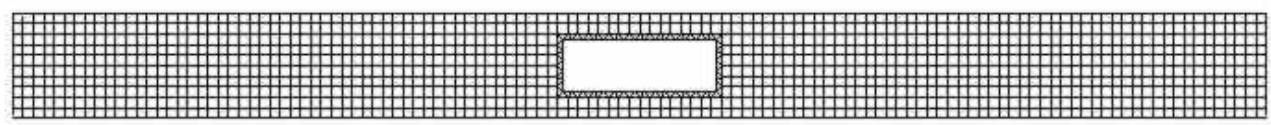

(c) View of the bridge with one web opening $(100 \times 50 \mathrm{~cm})$.

Figure 1: Bridge model.

\section{PARAMETRIC STUDY}

In the present investigation, all steel beams are built-up I-beams (non-compact). All web openings are concentric to the mid-height of the sections and symmetric about the mid-span of the steel bridge. For beams with multiple web openings, buckling of web posts may be critical when the openings are closely spaced. In this study and for multiple openings, the distances between the edges of the openings are $1.0 \mathrm{~h}_{\mathrm{w}}$, where $\mathrm{h}_{\mathrm{w}}$ is the web height. For perforated sections with these geometrical dimensions, it is generally considered that local buckling in the tee sections at the perforated sections is not critical. This in agreement with Liu and Chung [5]. 
A large number of finite element models (133 models) were constructed, and normalizing techniques were used to help generalize the results. When investigating the effect of web openings on the behaviour of steel I-girder bridge, both square and rectangular web openings are considered. Also, the effect of multiple web openings along the span of bridge models is studied. Three different ratios of web opening height $\left(h_{o}\right)$ to web height $\left(h_{w}\right)$ are investigated; $h_{o} / h_{w}=0.3,0.5$ and 0.7. Furthermore, the effect of horizontal reinforcement is considered. Indeed, the area of reinforcement (horizontal stiffener) $\mathrm{A}_{\mathrm{r}}$, above and below the web openings is recommended to be 0.3 $A_{f}$, where $A_{f}$ is the area of I-beam flange, and the projection of reinforcement beyond the edge of an opening (anchorage length of the reinforcement) should not be less than $15 \mathrm{~cm}$, [9]. In this study, three ratios of $\mathrm{A}_{\mathrm{r}} / \mathrm{A}_{\mathrm{f}}$ are considered; $\mathrm{A}_{\mathrm{r}} / \mathrm{A}_{\mathrm{f}}=0.0,0.15$ and 0.3 which represent web openings without reinforcement, web openings with reinforcement on one side only and web openings with reinforcement on two sides, respectively. For all models, the maximum deflection at mid span and the first twenty natural frequencies of the system are calculated with the physical and mechanical properties mentioned above. Typical web openings of the bridge model with reinforcements are shown in Fig. (2).

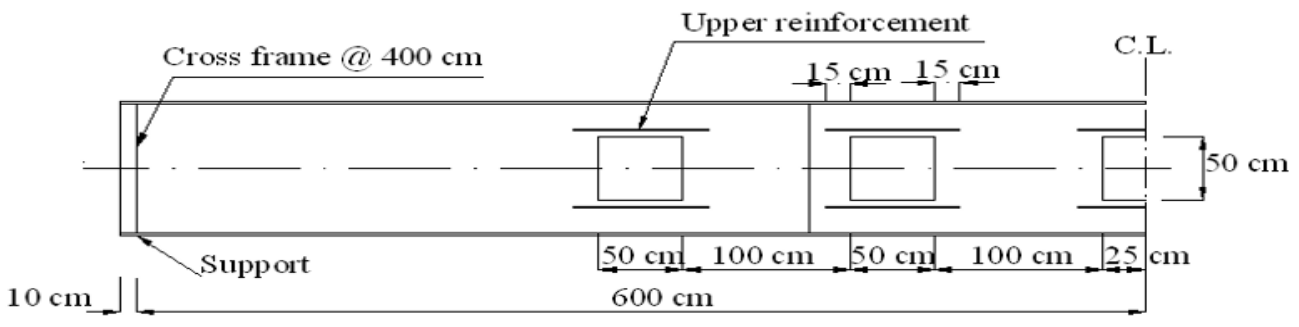

(a) 5 square web openings $(50 \times 50 \mathrm{~cm})$.

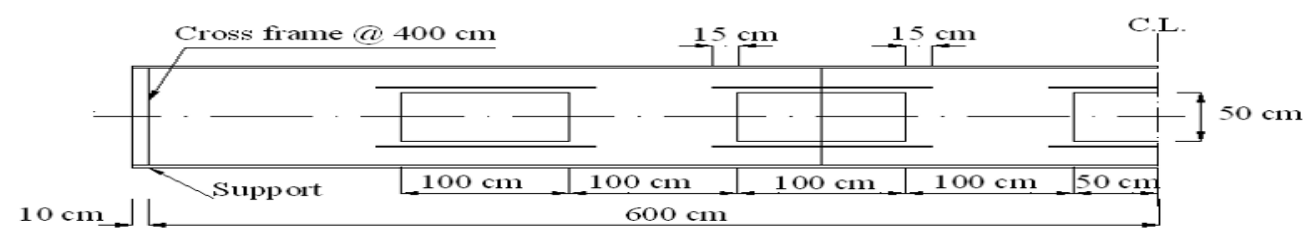

(b) 5 rectangular web openings $(100 \times 50 \mathrm{~cm})$.

Figure 2: Typical web openings of the bridge model with reinforcements.

\section{RESULTS AND DISCUSSIONS}

The following description summarizes the effects of rectangular web openings on deflection and free vibration response of steel I-beam bridges.

\subsection{Static Deflection at Mid Span}

In the following investigation, the maximum deflection at mid-span is calculated for each model. The percentage change in deflection of steel I-beam bridge is calculated as follows: 
Percentage change in deflection $=\left(\frac{\Delta_{p}-\Delta_{i}}{\Delta_{i}}\right) \times 100$,

where $\Delta_{p}$ and $\Delta_{i}$ are the deflections of perforated and intact system, respectively.

\subsection{Large web openings $\left(h_{0} / h_{w}=0.7\right)$}

Figure 3 shows the percentage change in deflections at mid-span due to large square web openings $\left(h_{o} / h_{w}=0.7\right)$ with different ratios of reinforcement area to flange area. Different number of square web openings are considered; 1, 3, 5 and 7 web openings $(70 \times 70 \mathrm{~cm})$. For un-reinforced web openings it is shown that the percentage change in deflection at mid span is almost zero for one web opening. This is due to the bottom lateral bracing effect on the rigidity of steel bridge. However, as the number of square web openings increases, the percentage change in deflection at mid span increases. Thus for 3, 5 and 7 web openings the percentage increase in deflections are; $12 \%, 31 \%$ and $59 \%$, respectively. It is clear that as the web openings become nearer to support, the percentage increase in deflection becomes greater. It is of interest to mention that for 7 web openings the distance between the edge of the opening near support and the support is less than $1.0 \mathrm{~h}_{\mathrm{w}}\left(0.55 \mathrm{~h}_{\mathrm{w}}\right)$ which is not recommended in design [9]. On the other hand, the horizontal stiffeners (reinforcements) have considerable effect to decrease the deflections at mid span of bridge models. Also, as the stiffness of reinforcements increases the maximum deflection of the bridge decreases. For reinforced square web openings with $\left(\mathrm{A}_{\mathrm{r}} / \mathrm{A}_{\mathrm{f}}=0.3\right)$, the defections at mid span of the bridge decrease to $48 \%, 66 \%$ and $74 \%$ of that of un-reinforced openings for 3,5 and 7 web openings, respectively. Moreover, for only one web opening the percentage change in deflection becomes negative which means that the deflection of the bridge with reinforced one square web opening $(70 \times 70 \mathrm{~cm})$ is less than that of the bridge without web opening.

Figure 4 shows the percentage change in deflections at mid-span due to large rectangular web openings $\left(\mathrm{h}_{\mathrm{o}} / \mathrm{h}_{\mathrm{w}}=0.7\right)$ with different ratios of reinforcement area to flange area. Different number of rectangular web openings are considered; 1,3 and 5 of size $(140 \times 70 \mathrm{~cm})$ with rectangularity ratio $2: 1$ and one web opening of size $(210 \times 70$ $\mathrm{cm})$ with rectangularity ratio $3: 1$. For un-reinforced web openings it is shown that the percentage change in deflection at mid span is almost zero for one web opening of size $(140 \times 70 \mathrm{~cm})$ or $(210 \times 70 \mathrm{~cm})$. This is due to the bottom lateral bracing effect on the rigidity of steel bridge model. However, as the number of rectangular web openings increases, the percentage change in deflection at mid span increases greatly. Thus for 3 and 5 web openings the percentage increases in deflections are; $61 \%$ and $180 \%$, respectively. It is clear that as the web openings become nearer to support, the percentage increase in deflections becomes greater. It important to mention that for 5 web openings $(140 \times 70 \mathrm{~cm})$ the distance between the edge of the opening near support and the support is less than $1.0 \mathrm{~h}_{\mathrm{w}}\left(0.50 \mathrm{~h}_{\mathrm{w}}\right)$ which is not recommended in steel design [9]. On the other hand, the horizontal stiffeners (reinforcements) have considerable effect to decrease the deflections at mid span of the steel bridges. Also, as the stiffness of reinforcements increases the maximum deflection of the bridge decreases. For reinforced rectangular web openings with $\left(\mathrm{A}_{\mathrm{r}} / \mathrm{A}_{\mathrm{f}}=0.3\right)$, the defections at mid span of the bridge decrease to $62 \%$ and $67 \%$ of that of un-reinforced openings for 3 and 5 web 
openings, respectively. Moreover, for only one rectangular web opening the percentage change in deflection becomes negative which means that the deflection of the bridge with reinforced one rectangular web opening is less than that of the bridge without web opening.

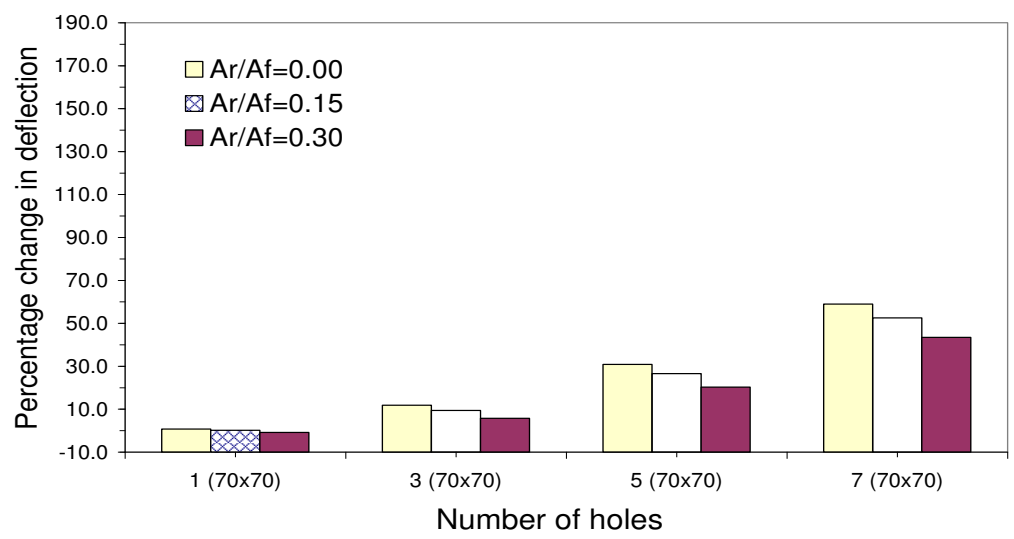

Figure 3: Effect of large square web openings $\left(\mathrm{h}_{\mathrm{o}} / \mathrm{h}_{\mathrm{w}}=0.7\right)$ on deflection at mid-span.

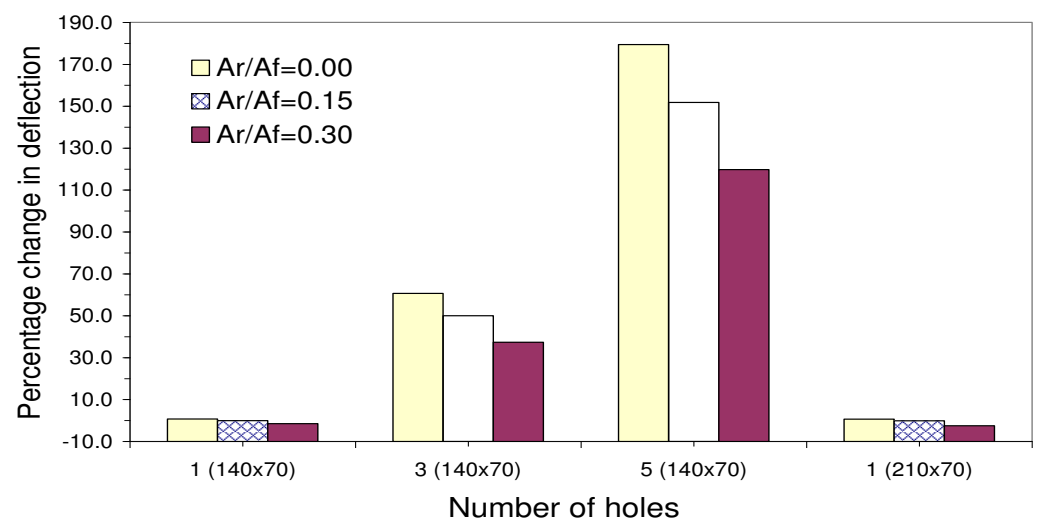

Figure 4: Effect of large rectangular web openings $\left(\mathrm{h}_{\mathrm{o}} / \mathrm{h}_{\mathrm{w}}=0.7\right)$ on deflection at mid-span.

In Figs. 3 and 4 it is clear that one rectangular opening $(210 \times 70 \mathrm{~cm})$ gives less deflection at mid span than 3 square web openings $(70 \times 70 \mathrm{~cm})$ although they have the same web opening area. Also, three rectangular openings $(140 \times 70 \mathrm{~cm})$ gives approximately the same deflection at mid span as 7 square web openings $(70 \times 70 \mathrm{~cm})$. This can be interpreted by the fact that the web opening at mid span of simply supported bridge is subjected to bending moment only. However, additional web openings are subjected to both bending moment and shear. So, it is recommended to use one rectangular web opening than using two or three square web openings in steel bridges with lateral bracings and to use horizontal stiffeners (reinforcements) above and below the web openings especially, for multiple web openings. 


\subsection{Medium web openings $\left(h_{0} / h_{w}=0.5\right)$}

To show the effect of medium square web openings $\left(h_{o} / h_{w}=0.5\right)$ with different ratios of reinforcement area to flange area on the maximum deflection of steel bridges, the relationship between percentage change in deflections at mid-span and the number of square web openings are plotted in Fig. 5. Different numbers of square web openings are considered; 1, 2, 3, 5 and 7 web openings $(50 \times 50 \mathrm{~cm})$. For un-reinforced web openings it is shown that the percentage change in deflection at mid span is almost zero for one web opening only. However, as the number of square web openings increases, the percentage changes in deflection at mid span increases with percentage increase in deflections of $10 \%$ for 7 square web openings. It is clearly seen that as the web openings become nearer to support, the percentage increase in deflections become greater. It is of interest to mention that for 7 web openings $(50 \times 50 \mathrm{~cm})$, the distance between the edge of the opening near support and the support is greater than $1.0 \mathrm{~h}_{\mathrm{w}}$ $\left(1.25 h_{w}\right)$. On the other hand, the horizontal stiffeners (reinforcements) have considerable effect to decrease the deflections at mid span of the steel bridge models. Also, as the stiffness of reinforcements increases the maximum deflections of the bridge decreases. For reinforced web openings with $\left(\mathrm{A}_{\mathrm{r}} / \mathrm{A}_{\mathrm{f}}=0.3\right)$, the defection at mid span of the bridge decrease to $0 \%, 15 \%, 50 \%$ and $68 \%$ of that of un-reinforced openings for 2, 3, 5 and 7 web openings, respectively. Moreover, for only one web opening the percentage change in deflection becomes negative which means that the deflection of the bridge with reinforced one square web opening $(50 \times 50 \mathrm{~cm})$ is less than that of the bridge without opening.

Figure 6 shows the percentage change in deflections at mid-span due to medium rectangular web openings $\left(h_{0} / h_{w}=0.5\right)$ with different ratios of reinforcement area to flange area. Different number of rectangular web openings are considered; 1, 3 and 5 of size $(100 \times 50 \mathrm{~cm})$ with rectangularity ratio $2: 1$ and one web opening of size $(150 \times 50 \mathrm{~cm})$ with rectangularity ratio $3: 1$. For un-reinforced web openings it is shown that the percentage change in deflection at mid span is almost zero for one web opening of size $(100 \times 50 \mathrm{~cm})$ or $(150 \times 50 \mathrm{~cm})$. However, as the number of rectangular web openings increases, the percentage change in deflection at mid span increases. Thus for 3 and 5 web openings $(100 \times 50 \mathrm{~cm})$ the percentage increase in deflections are; $8 \%$ and $22 \%$, respectively. It is clear that as the web openings become nearer to support, the percentage increase in deflections become greater. It is of interest to mention that for $5 \mathrm{web}$ openings $(100 \times 50 \mathrm{~cm})$ the distance between the edge of the opening near support and the support is greater than $1.0 \mathrm{~h}_{\mathrm{w}}\left(1.5 \mathrm{~h}_{\mathrm{w}}\right)$ which is recommended in design. On the other hand, the horizontal stiffeners (reinforcements) have considerable effect to decrease the deflections at mid span of the steel bridge models. Also, as the stiffness of reinforcements increases the maximum deflection of the bridge decreases. For reinforced web openings with $\left(A_{r} / A_{f}=0.3\right)$, the defections at mid span of the bridge decrease to $51 \%$ and $69 \%$ of that of un-reinforced openings for 3 and 5 web openings $(100 \times 50 \mathrm{~cm})$, respectively. Moreover, for only one rectangular web opening the percentage change in deflection becomes negative which means that the deflection of the bridge with reinforced one rectangular web opening $\left(h_{0} / h_{w}=0.5\right)$ is less than that of the bridge without opening. 


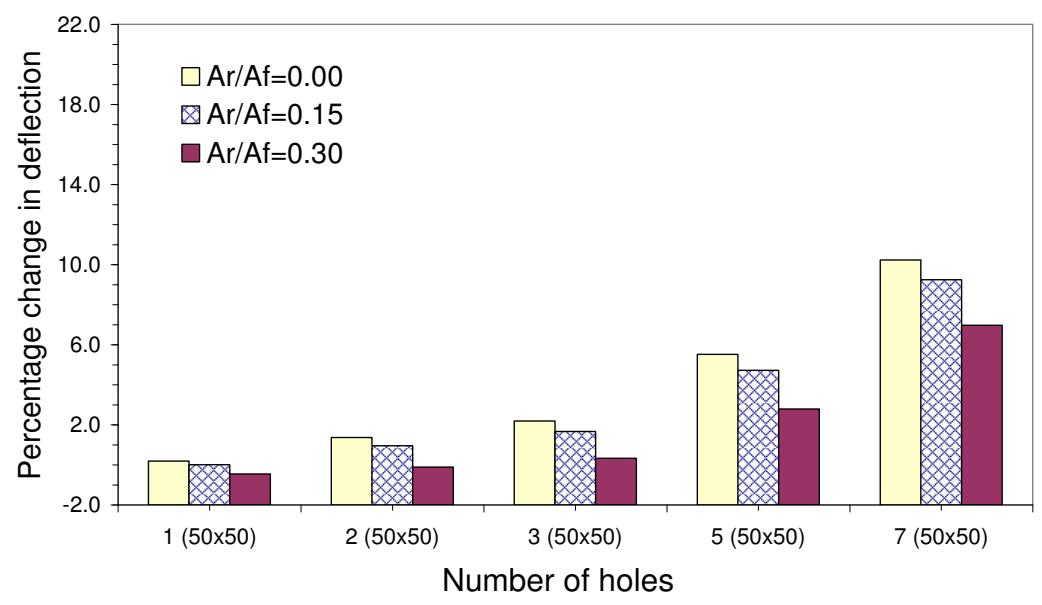

Figure 5: Effect of square medium web openings $\left(h_{0} / h_{w}=0.5\right)$ on deflection at midspan.

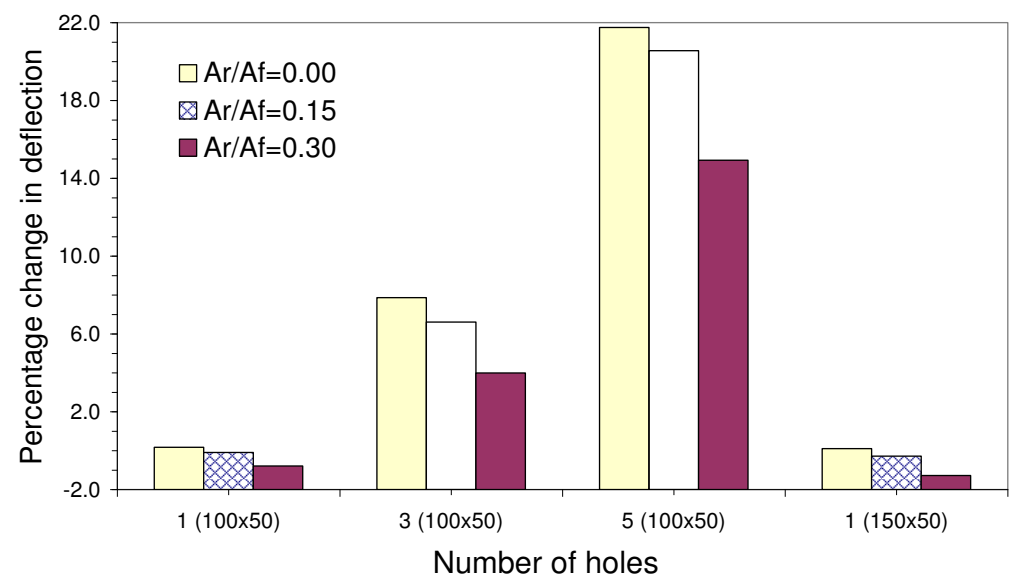

Figure 6: Effect of rectangular medium web openings $\left(h_{\mathrm{o}} / h_{w}=0.5\right)$ on deflection at mid-span.

In Figs. 5 and $\mathbf{6}$ it is clear that one rectangular opening $(150 \times 50 \mathrm{~cm})$ gives less deflection at mid span than three square web openings $(50 \times 50 \mathrm{~cm})$ although they have the same web opening area. Also, one rectangular opening $(100 \times 50 \mathrm{~cm})$ gives less deflection at mid span than two square web openings $(50 \times 50 \mathrm{~cm})$ although they have the same web opening area. This can be interpreted by the fact that the web opening at mid-span of simply supported bridge is subjected to bending moment only. However, additional web openings are subjected to both bending moment and shear. So, it is recommended to use one rectangular web opening than two or three square web openings in steel bridges with lateral bracings. 


\subsection{Small web openings $\left(h_{0} / h_{w}=0.3\right)$}

To determine the effect of small square web openings $\left(h_{o} / h_{w}=0.3\right)$ with different ratios of reinforcement area to flange area on the maximum deflection of steel bridges, the relationship between percentage change in deflections at mid-span and the number of square web openings are plotted in Fig. 7. Different numbers of square web openings are considered; 1, 3, 5 and 7 web openings $(30 \times 30 \mathrm{~cm})$. Figure 8 illustrates the percentage change in deflections at mid-span due to small rectangular web openings $\left(h_{\mathrm{o}} / \mathrm{h}_{\mathrm{w}}=0.3\right)$ with different ratios of reinforcement area to flange area. Different number of rectangular web openings are considered; 1,3 and 5 of size $(60 \times 30 \mathrm{~cm})$ with rectangularity ratio $2: 1$ and one web opening of size $(90 \times 30 \mathrm{~cm})$ with rectangularity ratio 3:1. It is clear that the results obtained for small web openings (square or rectangular) are similar to that obtained for medium or large web openings.

From Figs. 3, 5 and 7 it can be easily seen that an increase in the ratio of web square opening height to web height leads to great increase in the maximum deflection of bridge model. Similar observation can be easily inferred from Figs. 4, 6 and 8 for rectangular web opening. So, it is recommended to minimize the height of the opening to be 0.5 of web height.

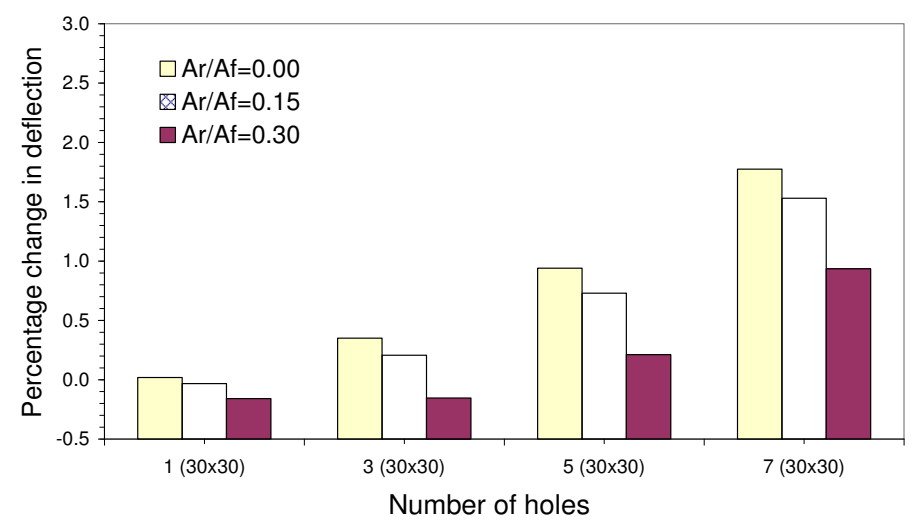

Figure 7: Effect of square small web openings $\left(h_{o} / h_{w}=0.3\right)$ on deflection at mid-span.

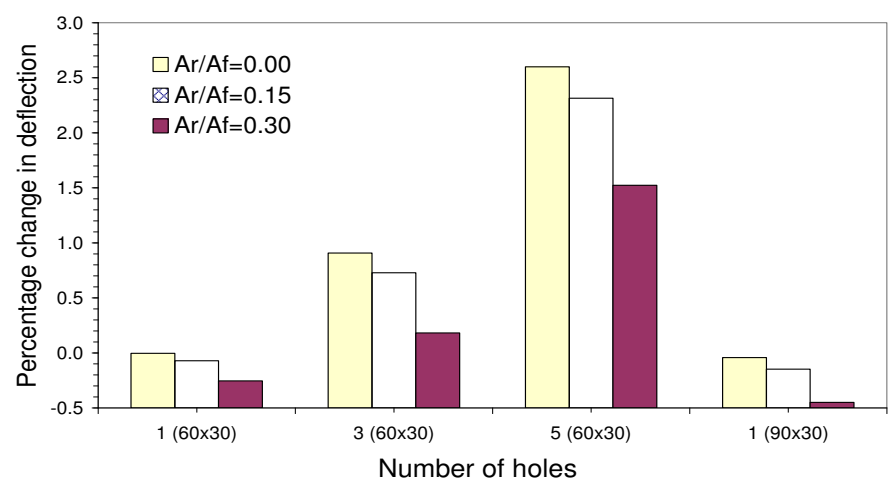

Figure 8: Effect of rectangular small web openings $\left(h_{o} / h_{w}=0.3\right)$ on deflection at midspan. 


\subsection{Free vibration response}

In the following investigation, the first twenty natural frequencies of each model are calculated. The percentage change in frequency of steel I-beam bridge is calculated as follows:

$$
\text { Percentage change in frequency }=\left(\frac{f_{p}-f_{i}}{f_{i}}\right) \times 100,
$$

where $f_{p}$ and $f_{i}$ are the frequencies of perforated and intact system, respectively.

\subsection{Large square web openings $\left(h_{o} / h_{w}=0.7\right)$}

Figure 9 shows the percentage change in frequencies due to large square web openings $\left(\mathrm{h}_{\mathrm{o}} / \mathrm{h}_{\mathrm{w}}=0.7\right)$ with different ratios of reinforcement area to flange area for different modes. Different number of square web openings are considered; 1,3 and 5 web openings $(70 \times 70 \mathrm{~cm})$ for different mode shapes. Seven square web openings $(70 \times 70$ $\mathrm{cm})$ are not considered here because the distance of the edge of the web openings near the support and the support will be less than $h_{w}$ which is not recommended in design as mentioned in Section 4.1.1. For un-reinforced web openings it is shown that the percentage change in frequency is almost zero for one square web opening. This is due to the bottom lateral bracing effect on the rigidity of steel bridge. However, as the number of square web openings increases, the percentage change in frequency becomes negative due to the reduction in stiffness and consequently a reduction in frequency. On the other hand, the horizontal stiffeners (reinforcements) have considerable effect to increase the frequencies of steel bridges with web openings. Also, as the stiffness of reinforcements increases the frequencies of the bridge increase slightly for all modes. Moreover, for only one web opening the effect of reinforcement is negligible. It is important to mention that when the percentage change in frequency becomes positive this means that the frequency of the bridge with reinforced web openings is greater than that of the bridge without web openings. Also, the effect of number of web openings and reinforcement is different from one mode to another one.

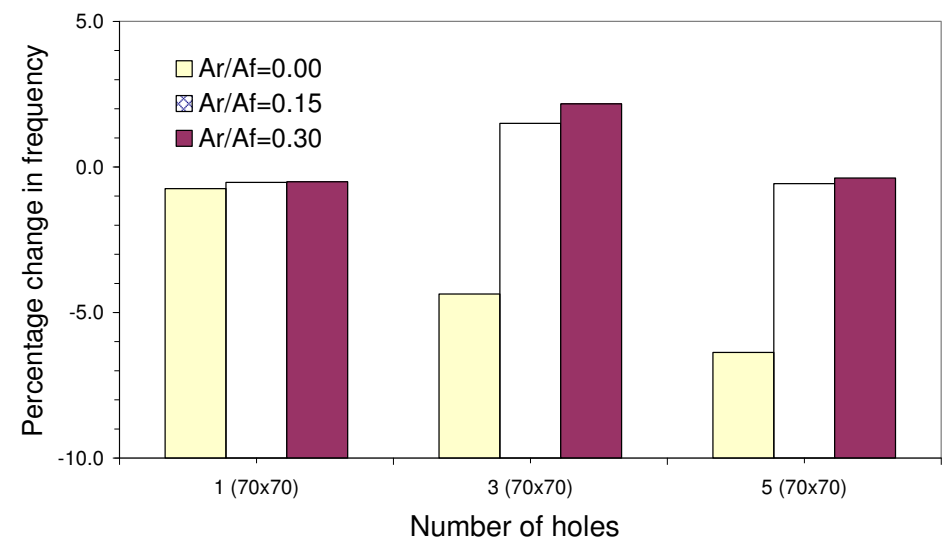

(a) Mode (1). 


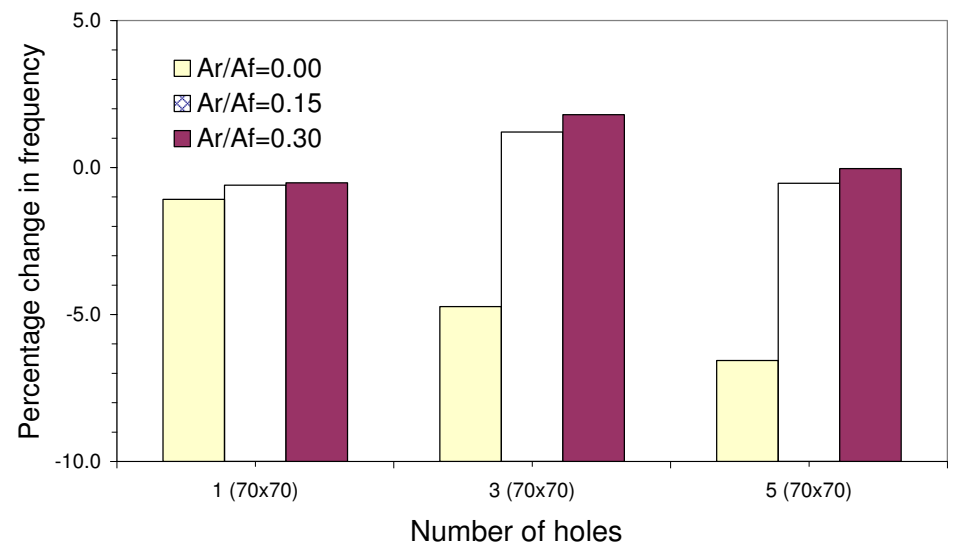

(b) Mode (5).

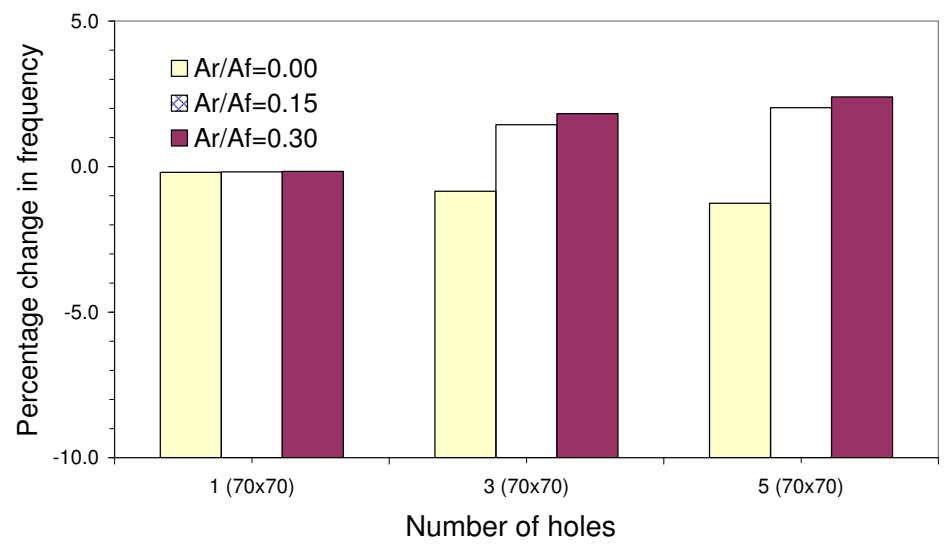

(c) Mode (10).

Figure 9: Effect of large square web openings $(\mathrm{ho} / \mathrm{hw}=0.7)$ on bridge frequencies.

\subsection{Large rectangular web openings $\left(h_{0} / h_{w}=0.7\right)$}

Figure 10 illustrates the percentage change in frequencies due to large rectangular web openings $\left(h_{0} / h_{w}=0.7\right)$ with different ratios of reinforcement area to flange area for different modes. Different number of rectangular web openings are considered; 1 and 3 of size $(140 \times 70 \mathrm{~cm})$ with rectangularity ratio $2: 1$ and one web opening of size $(210 \times 70$ $\mathrm{cm})$ with rectangularity ratio $3: 1$. Again, five rectangular web openings $(140 \times 70 \mathrm{~cm})$ are not considered here because the distance between the edge of the web openings near the support and the support will be less than $h_{w}$. For un-reinforced web openings it is shown that the percentage change in frequencies is small for one web opening of size $(140 \times 70 \mathrm{~cm})$ or $(210 \times 70 \mathrm{~cm})$. This is due to the bottom lateral bracing effect on the rigidity of steel bridge. However, as the number of rectangular web openings increases, the percentage changes in frequencies decrease. On the other hand, the horizontal stiffeners (reinforcements) have considerable effect to increase the frequencies of the steel bridges. Also, as the stiffness of reinforcements increases the frequencies of the bridge increase slightly. Moreover, when the percentage change in frequency becomes 
positive this means that the frequency of the bridge with reinforced rectangular web opening is greater than that of the bridge without web opening. Again, the effect of number of web openings and reinforcement is different from one mode to another one.

In Figs. 9 and $\mathbf{1 0}$ it is clear that one square or rectangular web opening has small effect on the frequencies of steel bridges. This can be interpreted by the fact that the web opening at mid-span of simply supported bridge is subjected to bending moment only. However, additional web openings are subjected to both bending moment and shear.

\subsection{Small and medium web openings $\left(h_{0} / h_{w}=0.3\right.$ or 0.5$)$}

Indeed, the results obtained for small web openings $\left(\mathrm{h}_{\mathrm{o}} / \mathrm{h}_{\mathrm{w}}=0.3\right)$ and medium web openings $\left(\mathrm{h}_{\mathrm{o}} / \mathrm{h}_{\mathrm{w}}=0.5\right)$ are similar to the results shown in Figs. 9 and 10. So, for better performance of free vibration response of steel bridges with bottom lateral bracings, it is recommended to use only one rectangular web opening at mid span than using more than one square web openings with the same opening height and to use (horizontal stiffeners) reinforcements especially for multiple web openings. Reinforcements with ratio $A_{r} / A_{f}=0.15$ has considerable effect to increase the bridge frequencies. However, increasing $\mathrm{A}_{\mathrm{r}} / \mathrm{A}_{\mathrm{f}}$ to be 0.3 will have less increase in bridge frequencies.

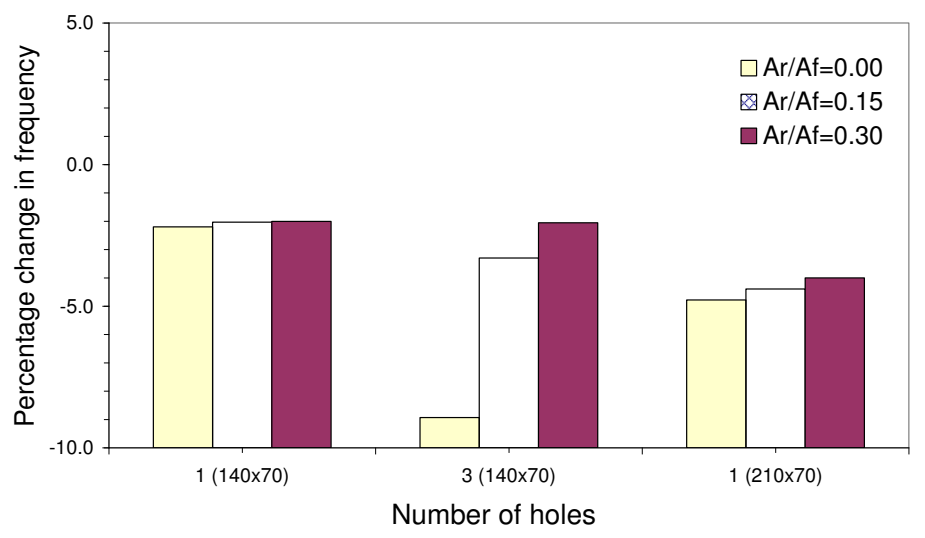

(a) Mode (1)

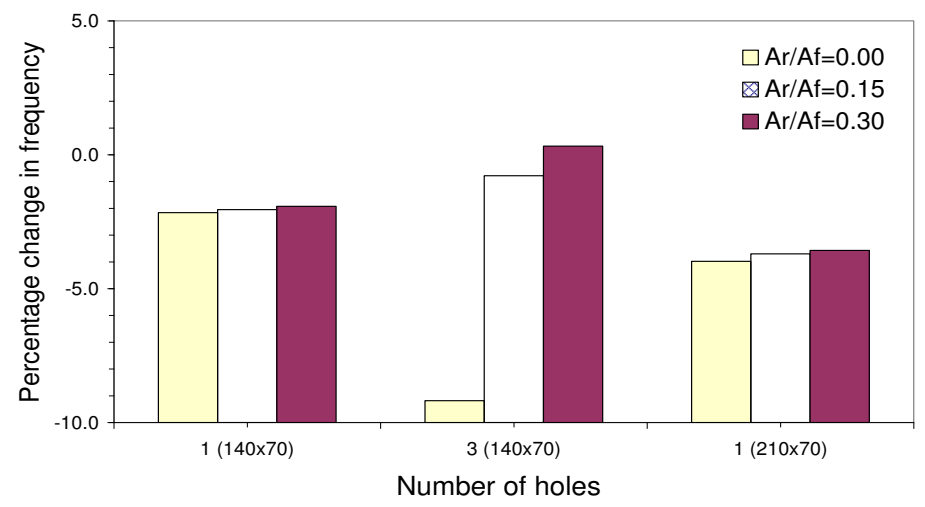

(b) Mode (5) 


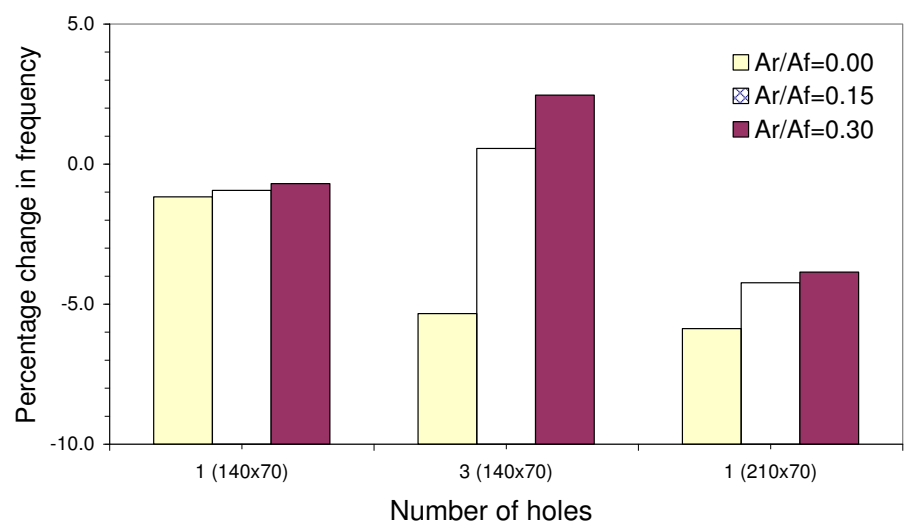

(c) Mode (10)

Figure 10: Effect of large rectangular web openings (ho/hw=0.7) on bridge frequencies.

\section{CONCLUSIONS}

Finite element modeling of structural steel I-girder bridge with cross frames and bottom lateral bracings is presented in this paper. A parametric study of the effect of web openings on static and dynamic response of steel bridges is presented. So, the free vibration response as well as the maximum deflections of bridge models is investigated. Three different ratios of web opening height $\left(h_{o}\right)$ to web height $\left(h_{w}\right)$ are investigated; $h_{\mathrm{o}} / h_{w}=0.3,0.5$ and 0.7 . Furthermore, the effect of horizontal stiffeners (reinforcements) is considered with different ratios of reinforcement area to flange area. Buckling and instability failures of the steel beams are not considered in the present analysis. The maximum deflection at mid-span and the first twenty natural frequencies of each model are calculated.

Based on the above results, it can be concluded that for steel bridges with cross frames and bottom lateral bracings, the existence of only one rectangular (square) web opening at mid span has almost negligible effect on the maximum deflections and small effect on the frequencies of bridge models. However, existence of more than one square or rectangular web openings leads to great increase in the deflection at mid span and considerable decrease in frequencies. Also, an increase in the ratio of web opening height to web height leads to great increase in the maximum deflection of bridge model. On the other hand, horizontal stiffeners (reinforcements) above and below web openings improves both static and dynamic response of steel bridge models especially, for multiple web openings. Thus, an increase in stiffness of reinforcements above and below web openings leads to a decrease in maximum deflections and an increase in bridge frequencies. However, the effect of reinforcement stiffness is more pronounced for static response.

\section{RECOMMENDATIONS}

Based on the previous analysis and conclusions of steel I-girder bridge with cross frames and bottom lateral bracings which is supposed to have rectangular web openings, it is recommended to: 
1) Use one rectangular opening than using more than one square openings with the same web opening height.

2) Use horizontal stiffeners (reinforcements) above and below web openings especially, for multiple web openings. The ratio of each reinforcement area to flange area should not less than 0.15 and it is preferable to be 0.3 ; with anchorage length $=15 \mathrm{~cm}$ beyond the edges of the opening.

3) Locate the opening at a distance from the support of at least the height of web.

4) Minimize the height of the opening to be not more than 0.5 of web height.

\section{REFERENCES}

[1] Chung, K. F., Liu, T. C. H. and Ko, A. C. H., "InVESTiGATION ON VierendeEL MECHANISM IN STEEL BEAMS WITH CIRCULAR WEB OPENINGS”, J. Constructional Steel Research, Vol. 57(5), pp. 467-490, (2001).

[2] Benitez, M. A., Darwin, D., and Donahey, R. C.: "Deflections of Composite BEAMS WITH WEB OPENINGS", J. Structural Engineering, ASCE, 124(10), pp. 1139-1147, (1998).

[3] Redwood, R. and Cho, S. H., "DESIGN OF STEEL AND COMPOSITE BEAMS WITH WEB OPENINGS", J. Constructional Steel Research, Vol. 25(1-2), pp. 23-41, (1993).

[4] Shan, M. Y., LaBoube, R. A., and Yu, W. W.: "BENDING AND SHEAR BEHAVIOUR OF WEB ELEMENTS WITH OPENINGS", J. Structural Engineering, ASCE, 122(8), pp. 854-859, (1996).

[5] Liu, T. C. H. and Chung, K. F., "STEEL BEAMS WITH LARGE WEB OPENINGS OF VARIOUS SHAPES AND SIZES: FINITE ELEMENT INVESTIGATION", $J$. Constructional Steel Research, Vol. 59, pp. 1159-1176, (2003).

[6] Hagen, N. C., Larsen P. K. and Aalberg. A.: "SHEAR CAPACITY OF STEEL Plate GIRDERS WITH LARGE WEB OPENINGS", PART I: MODELING AND SIMULATIONS", J. Constructional Steel Research, Vol. 65, pp. 142-150, (2009).

[7] Hagen, N. C. and Larsen, P. K.: "SHEAR CAPACITY OF STEEL PLATE GIRDERS WITH LARGE WEB OPENINGS", PART II: DESIGN GUIDELINES”, J. Constructional Steel Research, Vol. 65, pp. 151-158, (2009).

[8] Fahmy, E. H.: “ANALYSIS OF COMPOSITE BEAMS WITH RECTANGULAR WEB OPENINGS”, J. Constructional Steel Research, Vol. 37, pp. 47-62, (1996).

[9] Chung, K. F. and Lawson, R. M.: "SIMPLIFIED DESIGN OF COMPOSITE BEAMS WITH LARGE WEB OPENINGS TO EUROCODE 4", J. Constructional Steel Research, Vol. 57, pp. 135-163, (2001).

[10] Park, J. W., Kim, C. H., and Yang, S. C.: "Ultimate Strength of RibBed Slab Composite BeAms With Web Openings”, J. Structural Engineering, ASCE, 129(6), pp. 809-816, (2003).

[11] Hassan, N. K.: "FleXural BeHAVIOUR OF COMPOSITE BEAMS WITH WEB OPENINGS", Tenth International Colloquium on Structural and Geotechnical Engineering, $10^{\text {th }}$ ICSGE, Cairo, Egypt, 22-24 April (2003).

[12] Maneetes, H. and Linzell, D.G.: "CROSS-FrAME AND LATERAL BRACING INFLUENCE ON CURVED STEEL BRIDGE FREE VibRATION RESPONSE", J. Constructional Steel Research, Vol. 59, pp. 1101-1117, (2003). 
[13] Abdo, M. A.-B.: "PARAMETRIC STUDY OF THE EFFECT OF CROSS-FRAMES AND LATERAL BRACINGS ON FREE VIBRATION RESPONSE OF HORIZONTALLY CURVED I-BEAM BRIDGES", J. Engineering Sciences, Faculty of Engineering, University of Assiut, 36(2), pp. 295-312, (2008).

[14] EGYPTIAN CODE OF PRACTICE FOR STEEL CONSTRUCTION AND BRIDGES (ECP), Code No. (205), 255 pp., (2001).

[15] MARC Analysis Research Corporation, Volumes; A, B, and C, Version 2001, (2001).

[16] MARC Analysis Research Corporation, Mentat User's Guide, Version 2001, (2001).

[17] Abdo, M. A.-B.: "PARAMETRIC STUDY OF THE EFFECT OF DEAD LOADS ON BEAM NATURAL FREQUENCIES", J. Engineering Sciences, Faculty of Engineering, University of Assiut, 36(5), pp. 1071-1083, (2008).

\section{تحليل الكباري الصلب ذات فتحات الأعصاب المستطيلة باستخدام نظرية العناصر المحددة}

إن الكباري والمباني الحديثة غالباً ما تتطلب عمل فتحات في العناصر الإنثائية لتمرير وتركيب بعض

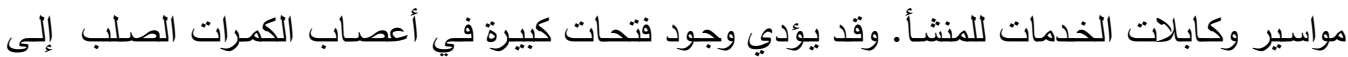
تغيير سلوك هذه المنشآت ويعتمد هذا على شكل وأبعاد ومكان هذه الفتحات. لذا يهتم هذا البحث بعمل تحليـل للكبـاري الصـلب والمدعمـة بالأحجبـة (Cross frames) وأنظمـة الســد العرضـية السـفلية والتي بها فتحات مستطيلة بالأعصداب باستخدام نظريـة (Bottom lateral bracing systems) العناصر المحددة. وقد نم عمل دراسة بارامترية لتأثير وجود فتحات مسنطيلة في أعصاب الكمرات بأبعاد وأعداد مختلفة على أقصى ترخيم (السلوك الاستاتيكي) وكذلك على التردد الطبيعي (السلوك الديناميكي)

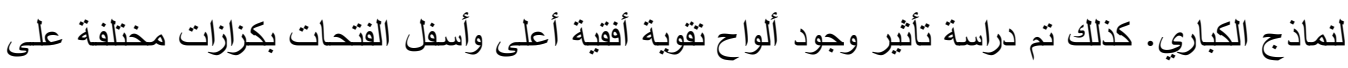

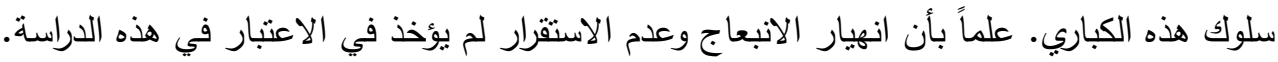

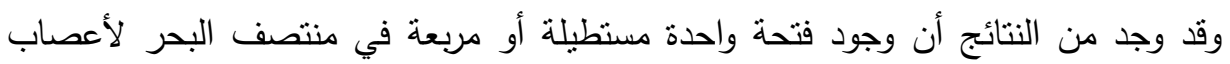

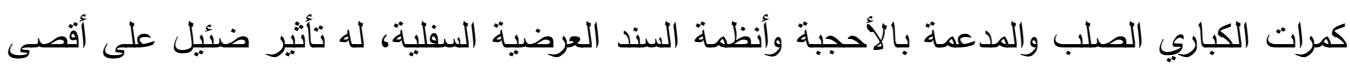

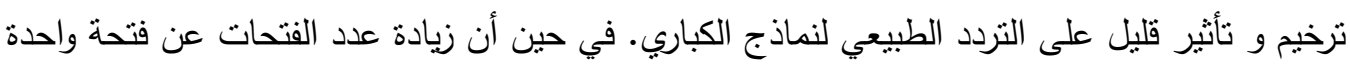
يؤدي إلى زيادة كبيرة في الترخيم ونقص يجب أخذه في الاعتبار في التزدد الطبيعي لنماذج الكباري.

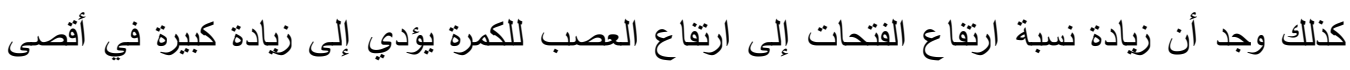
ترخيم. ومن ناحية أخرى، أظهرت نتائج التحليل العددي أن وجود ألواح النقوية الأفقية (أعلى وأسفل

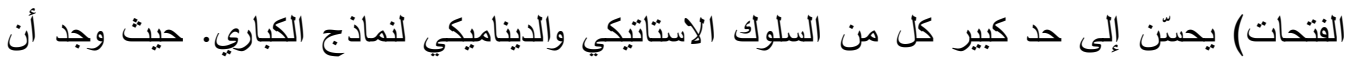


زيادة كزازة ألواح الثقوية يقلل من أقصى ترخيم ويزيد من التردد الطبيعي لنماذج الكباري، ولكن تأثير

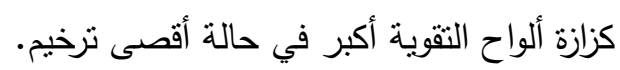

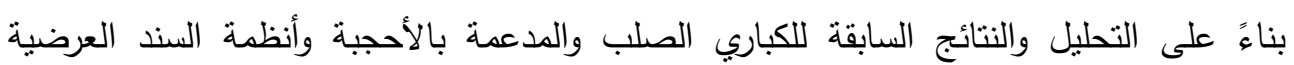

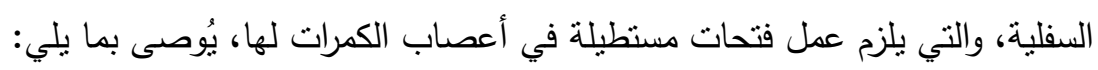

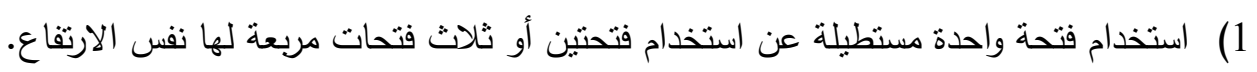

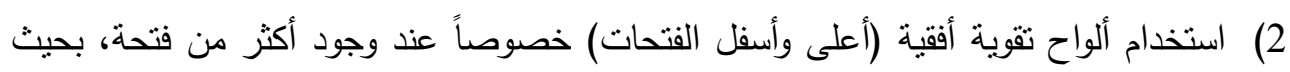
لاتقل نسبة مساحة كل لوح عن 0.15 من مساحة الثفة ويفضل أن تكون

$$
\text { الرباط على جانبي الفتحة عن } 15 \text { سم. }
$$

3) وضع الفتحات بحيث لاتقل المسافة بينها وبين الدعامة عن عمق عصب الكمرة. 4) تقليل ارتفاع الفتحات بحيث لايتعدى 0.50 عمق عصب الكمرة. 